\title{
Effects of Decentralized Health Care Financing on Maternal Care in Indonesia ${ }^{\dagger}$
}

\author{
Renate Hartwig
}

University of Namur \& University of Passau

\section{Robert Sparrow ${ }^{\S}$}

Wageningen University, Erasmus University Rotterdam, Australian National University

\section{Sri Budiyati, Athia Yumma, Nila Warda, Asep Suryahadi}

SMERU Research Institute

\author{
Arjun S. Bedi
}

Erasmus University Rotterdam

Running title: Decentralization and Maternal Care

\footnotetext{
${ }^{\dagger}$ The DHO survey used for this study was funded by the EU-FP7 research grant HEALTHF2-2009-223166-HEFPA on 'Health Equity and Financial Protection in Asia (HEFPA)'. We thank Michael Grimm, Kristen Stokes, two referees, as well as seminar and conference participants at the Forum Kajian Pembangunan in Jakarta, the ANU Indonesia Study Group, Wageningen UR, the University of Canberra, the University of Namur, Sebelas Maret University, Gadjah Mada University, the Nordic Conference on Development Economics in Copenhagen, the International Health Economics Association Conference in Milan and the Indonesian Regional Science Association Conference in Denpasar for useful comments and feedback. All errors are our own.

${ }^{\S}$ Corresponding author: Robert Sparrow, Wageningen University, Development Economics Group, Hollandseweg 1, 6706 KN Wageningen, The Netherlands. Phone: +31-317-484668. Email: robert.sparrow@wur.nl.
} 


\begin{abstract}
We exploit variation in the design of sub-national health care financing initiatives in Indonesian districts to assess the effects of these local schemes on maternal care from 2004 to 2010. The analysis is based on a district pseudopanel, combining data from a unique survey among District Health Offices with the Indonesian Demographic and Health Surveys, the national socioeconomic household surveys and the village census. Our results show that these district schemes contribute to an increase in antenatal care visits and the probability of receiving basic recommended antenatal care services for households that are not targeted by the national health insurance programs. We observe a decrease in home births. However, there is no effect on professional assistance at birth. We also observe variation in scheme design across districts as well as constraints to the effectiveness of local schemes. Including antenatal and delivery services explicitly in benefit packages and contracting local rather than national health care providers increases the effects on maternal care. Increasing population coverage reduces effectiveness, delineating limitations to local funding and risk pooling. Furthermore, we do not find any effects for districts outside Java and Bali, where access to basic health care remains a key policy concern.
\end{abstract}

Key words: Health Care Financing, Decentralization, Maternal Health Care, Indonesia.

JEL codes: I13, I18. 


\section{Introduction}

In the last decade, a large number of local health care financing schemes implemented and operated by district governments came into being in Indonesia. These schemes collectively known as Jamkesda (Jaminan Kesehatan Daerah - Regional Health Insurance), have been driven by two policy reforms implemented in the early 2000s. Indonesia's far reaching decentralization reforms in 2001 granted district governments larger fiscal and political autonomy also transferring a large part of public service delivery to district governments. In 2005 , the national government introduced subsidized social health insurance for the poor as a first step towards universal health coverage (UHC). The social health insurance however still left many households without coverage, particularly those in the informal sector, that fall outside the poorest segment. It is in response to this coverage gap that many district governments, exercising their relative autonomy introduced local health care financing schemes. However, despite the common motivation and institutional context the schemes vary greatly in scope and design (Gani et al. 2008, 2009; Sparrow et al. 2016).

At the time when many of the Jamkesda schemes were introduced, maternal health was and still remains a key policy concern in Indonesia. In the past decade maternal mortality has remained stubbornly above 200 per 100,000 births, which is twice as high as the MDG target that the country had and also represents one of the highest maternal mortality rates in Southeast Asia. Similarly, neonatal mortality has remained high at 19 per 1,000 births. The high maternal and neonatal mortality is generally attributed to the lack of skilled attendance at birth, inadequate referrals to health care facilities and the quality of antenatal care (ANC) services (e.g. Achadi et al. 2014). Most of the neonatal and maternal deaths however are preventable (UNICEF 2012). Studies, for example, estimate that about 20-30 percent of maternal deaths can be prevented with appropriate care during pregnancy (Ekman et al. 2008). In 
Indonesia, neonatal mortality is estimated to be about five times higher for children who do not receive antenatal care than children benefiting from these services (UNICEF 2012).

Maternal health is a world wide concern. Internationally, countries have experimented with different mechanisms (e.g. subsidies ${ }^{1}$, vouchers ${ }^{2}$ and conditional cash transfers $\left.(\mathrm{CCTs})^{3}\right)$ to improve access and use of maternal health care services, though, with ambiguous results (see Broghi et al. 2006; Kruk et al. 2007; Comfort et al. 2013; Dzakpasu et al. 2014; Glassman et al. 2013; Mohanan et al. 2016; For a systematic review see Murray et al. 2014). A few studies have also looked at the effect of insurance on the utilization of maternal health services. ${ }^{4}$ Mensah et al. (2010) assess the effects of the national health insurance scheme in Ghana, while Long et al. (2010) study the New Co-operative Medical System in China. Both these cross-section based studies document improved access to maternal health care which they attribute to insurance. In Ghana, for example, Mensah et al. (2010) find that health insurance leads to an increase in the likelihood of using antenatal care by 13 to 15 percentage points; an increase in facility based deliveries by 12 to 18 percentage points, and an increase in births assisted by a trained professional by 14 percentage points. While the authors note less complications during births, they do not find substantial improvements in the quality of antenatal care services used, i.e. on blood and urine testing. In China, Long et al. (2010) find increases in antenatal care and an increase in facility based deliveries from 45 to 80 percent. In a follow-up study the authors argue that health insurance coverage may also facilitate the overuse of non-medical caesarian sections with insured women being 1.3 times more likely to have a caesarian (Long et al.

\footnotetext{
${ }^{1}$ See e.g. De Allegri et al. (2012).

${ }^{2}$ See e.g. Ahmed and Khan 2011; Bellows et al. 2011; Obare et al. 2013; Van de Poel et al. 2014 .

${ }^{3}$ See e.g. Lim et al. 2010; Lin and Shah Salehi 2013; Powell-Jackson and Hanson 2012.

${ }^{4}$ So far, studies that have investigated the effect of insurance on the utilization of maternal health services specifically are scarce and do not establish a causal relationship (for a systematic review see Comfort et al. 2013).
} 
2012).

Large scale insurance schemes as in Ghana and China are still rare in developing countries. In many countries health insurance schemes remain fragmented and often operate only at a community level (Lagomarsino et al. 2012). The advantage of community or regional schemes which operate at a decentralized level is that they are arguably much closer to the target population and therefore also better positioned to respond to the needs of the population (see e.g. Skoufias et al. 2011). Conversely, local schemes may suffer from a lack of financial and human resources, and limited administrative capacity and technical expertise. So far, however, there is little empirical evidence on the performance of decentralized insurance schemes particularly with respect to maternal and child health care. The current policy context in Indonesia thus offers a unique opportunity to study the effects of such decentralized schemes.

There are several channels through which local health care financing schemes may affect maternal care: First, there is likely to be a direct effect on access to antenatal care and delivery assistance if these services are explicitly covered in the local schemes' benefit packages, reducing the financial barrier to these services. Second, there could be indirect effects of the Jamkesda on maternal health care even when antenatal care and delivery services are not directly covered by these schemes. For example, the effect could run through increased exposure to health care providers due to greater use of other services covered by the insurance, thereby improving awareness and trust, and leading to a reallocation of health budgets at the household level to maternal care. The reimbursement mechanism used for the health care service providers could lead to a quality or supply impulse at facility level, for example, when health care service providers might have a greater chance of being reimbursed. Finally, the introduction of the Jamkesda schemes could be accompanied by higher investments in the local health infrastructure at the district level and facilitate access through better health infrastructure. 
In this paper we provide evidence on the first mechanism outlined, as well as indicative evidence on improvements in the quality of services (fourth mechanism mentioned). More specifically, this paper investigates the effectiveness of the Jamkesda health care financing schemes in improving access to maternal health care services. The Jamkesda schemes have common political and institutional origins. Nevertheless, they are independent initiatives by district governments and a result of their autonomy based on Indonesia's decentralization law. As a result, the Jamkesda schemes vary greatly in their design. Therefore, we first concentrate on the average effects of these schemes before investigating the heterogeneity in the design of these schemes.

The paper contributes to the scant literature on the effects of health care financing and access to maternal care. First, the available data allow us to employ a more robust identification strategy and control for unobserved heterogeneity. Second, the detailed information on the local policy design provides an opportunity to assess the channels through which service delivery is affected. Finally, this is one of the few studies that also investigates differences in institutional and policy design within a single country context (see e.g. Faguet 2004; Akin et al. 2007; Galiani et al. 2008).

The study combines data from a unique survey of District Health Offices (DHOs) - which are responsible for the implementation of the district health policies - with the Indonesian Demographic and Health Surveys (IDHS) from 2007 and 2012, the annual Indonesian Socio-economic Survey (SUSENAS), and the Village Infrastructure Survey (PODES). The DHO survey provides detailed information on the design of the local schemes, such as the year of implementation, benefits package, premiums and co-payments, institutional arrangements, management and provider contracting. Our identification strategy exploits variation in local health financing reforms across districts and year of birth of children under 5 years of age. Using district-level fixed effects specifications, we find that local health care financing initiatives increase antenatal care visits for 
households that are not targeted by the national (subsidized) health insurance programs. Improvements in antenatal care are also observed in terms of the depth of antenatal services provided. The variation in design features of the schemes appears to be a source of impact heterogeneity. The observed positive effects of local health care financing schemes is driven by those schemes that explicitly include antenatal care in the benefit package. Finally, our results also point to constraints of the local schemes. We find no effects on the number of births attended by a trained professional, and we do not find any effects for remoter districts where concerns about access to basic health care are most prominent. Furthermore, contracting providers outside provincial and national health care providers, and increasing population coverage, reduces the impacts on maternal care, presumably by spreading limited local resources too thinly.

The remainder of this paper is structured as follows. Section 2 provides a brief background on the policy context. Section 3 presents the data and key variables. Section 4 outlines the empirical strategy. The results are discussed in Section 5 and Section 6 concludes.

\section{Context}

While social health insurance has been established in Indonesia for decades, this has been exclusively available to the formal sector, i.e. the public service, military and police, and the formal private sector. Prior to 2005 the main health care financing policy instrument for the poor was the Health Card program (a remnant from the 1998 Asian Financial Crisis social safety net) that provided targeted health care fee waivers at public providers to about 10 percent of the population. In 2005 the Askeskin (Asuransi Kesehatan untuk Keluarga Miskin - Health Insurance for Poor Families) program was introduced, as a first step towards a long term objective of universal health insurance coverage in Indonesia (Sparrow et al., 2013). In 2008 the program was expanded under 
the name Jamkesmas (Jaminan Kesehatan Masyarakat - Public Health Insurance) to cover not only the poor but also the near poor. Households enrolled in these programs were entitled to a comprehensive health care package at public and selected private providers, with the premiums fully subsidized by the government.

About 10 to 15 percent of the population in Indonesia were covered by formal sector health insurance schemes. The Askeskin and Jamkesmas reforms expanded insurance coverage by a further 30 percent and thus nearly 45 percent of the population was covered by national health insurance schemes. The reforms, however, still excluded a large part of the population in the informal sector. These households were not considered sufficiently destitute to be targeted for the subsidized insurance, while also having no access to formal sector social health insurance or private insurance. Many district governments acknowledged this coverage gap of the national schemes and responded by establishing local health care financing schemes - the Jamkesda - to particularly target those left out.

The local health care financing schemes were not only motivated by existing coverage gaps; many were also driven by political opportunity (Aspinal, 2014). With the introduction of direct elections for district regents (rural districts) and mayors (municipalities) in 2005, free health care became a prominent feature in election campaigning. As a consequence, the number of local health care financing schemes increased significantly after 2005 when the first district elections were held.

The Jamkesda schemes were similar in that they are financed out of district government budgets (often with support from the province). Furthermore, the schemes were typically set up as a social insurance program following the national Jamkesmas model with the district fully subsidizing the premiums. For about 30 percent of the Jamkesda management and administration was outsourced to the national insurance carrier PT Askes or an external party, but 
most were managed by the DHOs or implementation agencies set up by the district governments. Despite these common features, there are also a number of differences in the scope of these schemes, for example, the benefits that are covered by the schemes, the health care providers contracted, and the legal endorsement (for further details see Sparrow et al. (2016), and section 3.1 of this paper).

As of January $1^{\text {st }}, 2014$, the Jamkesmas program and the formal sector social health insurance schemes have been consolidated in a new national health insurance (Jaminan Kesehatan Nasional (JKN)). The new national scheme combines the beneficiaries of the former Jamkesmas and the formal sector programmes, with the objective of reaching universal coverage by 2019. In the first two years, however, progress with voluntary enrolment for the nonsubsidized informal sector has been slow and subject to adverse selection (Sato and Damayanti 2015). Currently it remains unclear if and how the existing local health insurance schemes will be incorporated into the new national policy by 2019 .

\section{Data}

\subsection{Data Sources}

For the empirical analysis we construct a district pseudo-panel for the period 2004-2010 combining data from 4 sources: (i) a unique survey conducted among District Health Offices (ii) the IDHS for 2007 and 2012, (iii) the SUSENAS for 2003-2009, and (iv) the PODES for 2003, 2006 and 2008.

The DHO survey was conducted through a combination of mail questionnaires and phone interviews with DHOs from December 2011 to April 2012. The DHOs are responsible for the implementation of the health policies of district governments, which include the Jamkesda schemes. The survey collected detailed information on these local schemes, including timing of implementation, 
benefit packages, intended beneficiaries and coverage, funding source, health service providers contracted and institutional design (legal endorsement and management). ${ }^{5}$

Out of a total of 442 districts that were contacted, 262 districts responded (60 percent). ${ }^{6}$ Figure 1 shows the geographic spread of the districts and their status in the DHO survey. Red areas are districts which were not contacted due to missing contact details. Yellow areas are districts which were contacted but did not respond. The blue and green areas are districts which responded to the survey. Green areas are districts which were not running a local health care financing scheme at the time of the survey. The districts that responded cover approximately 58 percent of the Indonesian population in 2010. The nonresponse rate is a cause of concern with regard to sample selection bias and the generalizability of the district survey. However, consistent with Sparrow et al. (2016), and as will be discussed later, we find no evidence of sample selection bias affecting our estimation results (see Section 4 for details).

The IDHS is a nationally representative survey that provides detailed information on households, individual health behaviour and other characteristics. The main survey respondents are women aged 15-49. For the analysis we rely on information gathered on children aged between 0 and 5 years of age. Due to the random sampling process of the IDHS data not all districts are represented in each survey wave. Combined, the two IDHS surveys sampled children from 234 of the 262 districts that responded to the DHO Survey.

The SUSENAS is a socio-economic survey conducted annually among a cross-section of approximately 200,000 households. The survey is representative at the district level and includes basic information on health care but is less detailed than the IDHS. For the purpose of our analysis, we use the SUSENAS to obtain information on the average health insurance coverage rates in districts.

\footnotetext{
${ }^{5}$ For a detailed description of the survey see Sparrow et al. (2016).

${ }^{6}$ Indonesia was made up of 497 districts at the time the DHO survey was conducted. 55 districts could not be contacted for the DHO survey because no contact details could be obtained for these districts.
} 
The PODES village census is conducted every two to three years and provides information on all rural villages and urban precincts in Indonesia, including details on infrastructure and availability of health care providers.

We merge the data from the DHO Survey with the pooled IDHS survey data based on a district identifier. Additional information on district characteristics and infrastructure are obtained from the SUSENAS and PODES, which have been collapsed to the district level.

The children included in our sample are aged between 0 and 5 years of age at the time of the survey (i.e. 2007 or 2012 respectively). The years of birth that we are considering for analysis range from 2004 to 2010 . In total we have 10,856 child-observations spread over 234 districts and two survey years. The combined data allows us to match the year of birth of the children to the presence and design characteristics of a Jamkesda scheme in that specific year. That is, the data constitutes a district pseudo-panel with variation in outcome variables and Jamkesda policy by year of birth and district. Due to inconsistencies in the SUSENAS questionnaires, we can get a complete set of consistent control variables only for children with year of birth from 2004 onward. The period under study ends in 2010 because of the introduction of the Jampersal (Jaminan Persalinan - Universal Delivery Care) program in 2011. This program provides free delivery assistance as well as free ante- and postnatal services for women that are not covered by other health insurance programs, including Jamkesda. Extending the analysis to 2011 might confound the Jamkesda impact estimates. The Jampersal program was discontinued in 2014 with the introduction of the national health insurance program (JKN). So far, there is limited evidence of the effect of Jampersal. ${ }^{7}$

\footnotetext{
${ }^{7}$ Achadi et al. (2014) conducted an assessment of the program in 2 locations - Garut and Depok - in 2013 and show that even in the third year of implementation, awareness about the program was low: $30 \%$ of the target population, i.e. women of child bearing age, were not aware of the program in the two districts. Furthermore, provider involvement in the two districts was low due to dissatisfaction with the fee structure and reimbursement from central government. There is also evidence of mis-targeting, as the use of Jampersal was higher among those women which were already covered by insurance. Finally, the study shows that Jampersal only had effects in Garut where institutional delivery coverage was still low (Achadi
} 
Table 1 shows descriptive characteristics for the pooled data. Our sample of children is gender balanced, with a male share of around 51 percent. The average age of mothers at the birth of the child included in the sample is 28 years, and mothers' education averages about 9 years. The mothers in the sample have on average 2.5 children, and 97 percent are married. The sampled children come from predominantly male headed households with on average 5.5 members. Just over half of the children live in rural areas.

With respect to the district features, we see substantial variation in key infrastructure characteristics. Over the three PODES surveys, about 62 percent of households are connected to the electricity grid, 24 percent of villages obtain drinking water through manual or electric pumps, and 64 percent are accessible by an asphalt road. With respect to health services, only 42 percent of villages have a doctor, while midwives and traditional birth assistants are found in 82 and 86 percent of the villages.

The vast majority of the Jamkesda schemes were rolled out between 2007 and 2010, following the introduction and expansion of the national social health insurance programs for the poor (i.e. Askeskin and subsequently Jamkesmas), and with the first directly elected district heads having taken office. By 2011 just over 97 percent of districts in our sample had introduced a Jamkesda scheme (Figure 2).

The districts also show a large degree of variation in Jamkesda design characteristics (Table 2). About 35 percent of the districts have Jamkesda schemes that cover prenatal and maternity care services, while 25 percent cover delivery services. Almost all the districts cover services provided at the local health centre (92 percent), and district and province/national hospitals (88 respectively 82 percent). Only a quarter also contracted private hospitals, mainly for referrals. Closing the coverage gap left by national insurance programs and achieving universal coverage is an objective of about a third of the schemes in et al. 2014). 
our sample.

Variation in institutional and operational design are discussed in more detail in Sparrow et al. (2016). They report that membership cards as proof of eligibility are used in only 26 percent of the districts, while 29 percent of districts have outsourced management of their Jamkesda program to a private insurer. The remainder are managed by the DHO, in most cases through special divisions or technical units. In 20 percent of the districts Jamkesda schemes have been endorsed by both the district head and the local parliament, which provides the strongest legal basis for the schemes as these cannot be abolished or amended without approval from the local parliament.

\subsection{Outcome variables}

Our empirical analysis of maternal and child health care concentrates on five measures: the number of antenatal care visits, having at least 4 antenatal care visits as advised by the World Health Organization (WHO), the place of delivery (whether a child was born at home), delivery assistance (whether the birth was attended by a trained professional, a village midwife or doctor), and the mode of delivery (whether the child was born by caesarian section) ${ }^{8}$ Before we explore the effect of the Jamkesda on these outcomes more systematically, Table 3 provides an overview of the development of these indicators from 2004 to $2010 .^{9}$

The average number of antenatal visits increases, from an average of just below 7 visits, by about 0.5 visits between 2004 and 2010 . This trend is also reflected in the share of reported pregnancies for which mothers sought at least 4 antenatal care visits, which increased from 81 to 87 percent. Births at home declined from 58 percent in 2004 to 39 percent in 2010, while births assisted by

\footnotetext{
${ }^{8}$ Ideally we would also look at child and maternal mortality rates. However, the IDHS does not contain the number of observations and reports of child and maternal mortality required to provide sufficient statistical power.

${ }^{9}$ Table A1 in the supplemental appendix shows the evolution of the outcome measures disaggregated by region and wealth status.
} 
a trained professional increase from 29 to 46 percent. With an increasing share of births at a health facility, the number of caesarean sections also increases from 6 percent in 2004 to 14 percent in 2010.

The antenatal care outcome measures only the frequency of visits. With an average of more than 4 visits, Indonesia does exceed the minimum standards set out by the WHO. However, the quality of the antenatal care received is of particular concern. The Ministry of Health of Indonesia recommends that quality antenatal care should include the following components: (i) height and weight measurements, (ii) blood pressure measurement, (iii) iron tablets, (iv) tetanus toxoid immunization, (v) abdominal examination, (vi) testing of blood and urine samples and (vii) information on the signs of pregnancy complications. Table 4 shows descriptive statistics for each of the components. For a number of individual components there is evidence of improvement over time. However, in 2010 for only 14 percent of the children born do mothers report having received the complete set of recommended services.

\section{Empirical Approach}

Even though Jamkesda schemes vary in their design, they have common political and institutional origins. Therefore, we first concentrate on the average effects of these schemes before investigating the heterogeneity in the design of these schemes. In order to assess the average effect of the Jamkesda schemes on maternal and child health care services we use a linear district fixed effects specification: ${ }^{10}$

\footnotetext{
${ }^{10}$ Linear models could be mis-specified for the binary and censored outcomes. Nevertheless, we apply a linear specification to control for district fixed effects and to not lose observations for districts with few DHS observations and limited variation in the outcome variables. We did estimate fixed effects Poisson (for antenatal care) and logit models (for home births, assisted deliveries and caesarean sections) as an alternative. These yielded qualitatively similar results. In addition, we apply the trimmed estimator suggested by Horrace and Oaxaca (2006), who argue that the potential bias in linear probability models increases with the proportion of predicted probabilities that falls outside the zero to one interval. They suggest a trimming estimator by dropping those observations outside the interval and re-estimating the linear model for the remaining sample. For the binary outcome variables 82 to 91 percent of predicted prob-
} 


$$
Y_{i k t}=\alpha+\beta J a m k e s d a_{k t-1}+D_{k t-1}^{\prime} \gamma+X_{i k t}^{\prime} \theta+\delta_{t}+\mu_{k}+\varepsilon_{i k t}
$$

where $Y_{i k t}$ represents one of the five outcome variables for child $i$ in district $k$ at year of birth $t$.

The main variable of interest is $J a m k e s d a_{k t-1}$, which is a dummy variable indicating whether a district has been operating a local health care financing scheme in the calendar year prior to the year of birth. We choose this lagged specification because the specific month in which Jamkesda schemes are introduced varies greatly and for many districts will not overlap with the IDHS recall period in the same year. Moreover, the use of antenatal care and any perceptions or decisions with regard to the mode of delivery and birth assistance are expected to be determined mostly in the months preceding the birth of a child, possibly overlapping with the previous calendar year. The coefficient $\beta$ can be interpreted as the average impact of the Jamkesda program after controlling for the coverage effects of an array of national schemes covered by the vector $\gamma$. The district indicators $D_{k t}^{\prime}$ include the share of the district population covered by each of the following programs: subsidized social health insurance Askeskin and Jamkesmas, the health card program, public sector health insurance, formal private sector social health insurance, private health insurance and other schemes. We further control for other basic district characteristics, such as the share of the population, the level of electrification, the main source of drinking water, road access, and the availability of trained health staff. The vector $X_{i k t}^{\prime}$ controls for child-, mother- and household characteristics reported in Table 1. Time invariant district characteristics are controlled for by including district fixed effects $\mu_{k}$, while $\delta_{t}$ controls for year fixed effects.

In addition to analysing the average effects of the Jamkesda schemes we abilities fall within the unit interval, while less than 1 percent of the sample shows predicted antenatal visits smaller than zero. Finally, the Horrace and Oaxaca trimmed estimator yields similar coefficients to the linear regressions for the unrestricted sample. Therefore, we present linear probability models in the paper. 
probe the heterogeneity in design characteristics $S$ that relate to the population and service coverage dimensions of the Universal Health Coverage (UHC) framework (World Health Organization, 2010):

$$
Y_{i k t}=\alpha+\beta J a m k e s d a_{k t-1}+S_{k t-1}^{\prime} \lambda+D_{k t-1}^{\prime} \gamma+X_{i k t}^{\prime} \theta+\delta_{t}+\mu_{k}+\varepsilon_{i k t}
$$

The vector $S_{k t-1}$ includes a dummy variable indicating if the program objective is to cover all the non-insured or not, the maternal health services covered by the benefit packages (antenatal care and delivery assistance) of the district schemes, and the type of providers contracted. Note that by design $S_{k t-1}=0$ if Jamkesda $a_{k t-1}=0$.

Equations (1) and (2) will yield unbiased estimates of Jamkesda in the absence of unobserved confounding factors. The district fixed effects eliminate any time invariant factors such as topography, institutions and endowments, while inclusion of individual and district level characteristics should minimize bias due to time variant omitted variables.

The main confounding factor that we do not control for in equations (1) and (2) is potential change in district public policy that coincides with the introduction of the Jamkesda schemes. Policy reforms are rarely isolated events and it is not unlikely that local health care financing initiatives are part of a larger reform agenda of local governments. In the specific case of the Jamkesda, indeed, Sparrow et al. (2016) show that the timing of local elections are a strong predictor of the timing of introducing Jamkesda. If these elections led to broader reforms then they may influence the outcome variables other than through Jamkesda. We test for this source of violation of the parallel trends assumption by including a dummy variable indicating whether a district has a directly elected mayor or regent in the year of birth $t$. The timing of the first direct elections for district heads differs per district as they are determined by 
the time of expiry of the appointed incumbents' term in office after 2005. This provides identifying variation over time and across districts. If our estimates are confounded by the influence of local elections and multiple policy reforms, then the results are expected to be sensitive to including the direct election variable.

To further investigate the presence of non-parallel trends, we estimate placebo regressions where we assess correlation between the outcome variables and next year's adoption of a Jamkesda scheme. These regressions are identical to Equation (1) except that we include Jamkesda $a_{k t+1}$ instead of Jamkesda $a_{k t-1}$. Statistical significance of the $\beta$ coefficients would be evidence of confounding trends.

Moreover, we also test whether the estimated effects are driven by fertility delays in expectation of the introduction of a Jamkesda scheme (see Table A2 for detailed results). ${ }^{11}$

Finally, we address the potential sample selection bias due to the nonresponse in the DHO survey (see Table A3). Although it is not necessarily our aim to generalize the results beyond the 58 percent of the Indonesian population that is covered by our data, we do want to get a sense of the extent to which our results are sensitive to the non-response. We estimate a selection probit for the probability that a child observed in the IDHS sub-sample lives in a district that is also covered by the DHO survey. An inverse Mills ratio is constructed from these estimates and included as an additional control variable in the district fixed effects regression. The probit includes the same $D_{k t}^{\prime}$ and $X_{i k t}^{\prime}$ control variables as in Equation (1), which are available for all districts irrespective of DHO survey response. To support identification of the selection model, we include the DHO survey enumerator fixed effects for each district as an additional explanatory variable in the selection equation. We argue that the enumerator interview skills may influence the DHO non-response probability, while there is no reason to expect that these skills are related to the outcome

\footnotetext{
${ }^{11}$ We do not find any systematic influence of the schemes, neither on desired fertility nor on actual births.
} 
variables in the IDHS surveys of 2007 and $2012 .{ }^{12}$

\section{Results}

Table 5 presents the average effects of the Jamkesda scheme based on the econometric specifications described above. Column (1) shows the $\beta$ coefficients for the different outcome variables in the base specification without covariates, column (2) shows the coefficients controlling for year fixed effects and individual characteristics, and column (3) is the full specification that also accounts for district characteristics. Columns (4) and (5) present estimates that are sensitive to the timing of local elections and sample selection, respectively.

The results in column (1) show that there is a positive correlation between the presence of a Jamkesda scheme and maternal care. That is, the number of antenatal care visits and the probability of receiving professionally trained birth assistance are higher, and the probability of delivering at home is lower in the presence of Jamkesda. However, this association seems to be mostly spurious correlation or driven by selection effects. As we add year fixed effects and control variables the correlation becomes weaker, especially when household characteristics are included.

The results in column (3) suggest that on average, the introduction of the Jamkesda schemes led to an increase in antenatal care utilization of 0.26 visits. Although this seems small compared to the level of utilization, as it is about 4 percent of the average number of visits in 2004 , it is still about half of the total increase in antenatal care observed between 2004 and 2010. While the effect on antenatal care is positive, we find no statistically significant effect on exceeding the 4 -visit threshold. There are also no substantial effects of Jamkesda on home deliveries, births assisted by a trained professional or birth by caesarean section.

\footnotetext{
${ }^{12}$ The enumerators were assigned as primary contact to a specific set of districts, with nonresponse rates per enumerator varying from 19 to 65 percent. There is no purposive spatial pattern in district allocation to enumerators, as each enumerator covered various regions of Indonesia to share the burden of long distance connection problems and different time zones within the team.
} 
The coefficients are small compared to the initial correlation shown in column (1) and imprecise.

The sensitivity analysis, columns (4) and (5), show that the estimates are robust, strengthening the interpretation of the results of the main specification (column (3)) as causal effects. We find no evidence of confounding policy effects through directly elected district heads, as the results reported in column (4) and column (3) are marginally different for all outcomes. Moreover, the placebo regressions show no evidence of other non-parallel trends. The coefficients for Jamkesda $a_{k t+1}$ are very small and not statistically significant (column (6)). ${ }^{13}$ The results are also not sensitive to including the sample selection term that corrects for the DHO survey non-response (column (5)). The enumerator fixed effects appear strong predictors of sample selection, yet the results in columns (3) and (5) are almost identical. ${ }^{14}$ This suggests that any differences between the sampled and non-response districts have been absorbed by the control variables and the district fixed effects.

Previous research has indicated that different regions in Indonesia are exposed to different health problems (UNICEF 2012). We therefore investigate the heterogeneity of the Jamkesda effects with respect to the rural-urban divide and across regions (i.e. Java and Bali compared to other islands). Due to the large number of results from this combination of outcome variables and subpopulations, we incorporated multiple hypothesis testing to reduce the probability of falsely rejecting the null. We calculated adjusted p-values that account for potential correlation between the outcome variables, following the stepdown procedure proposed by Romano and Wolf (2016). The results presented in Table 6 indicate that the increase in antenatal care visits is mainly driven by increased access on Java and Bali, relatively populous and wealthy islands compared to other regions. ${ }^{15}$ This effect for Java and Bali is sufficiently strong

\footnotetext{
${ }^{13}$ The placebo regression results for all outcomes and sub-populations are reported in the supplemental appendix (see Tables A4 and A5).

${ }^{14}$ Detailed estimates are provided in the supplemental appendix (see Table A3).

${ }^{15}$ Each coefficient in Table 6 reflects the $\beta$ coefficient of a separate regression. The clustered
} 
that we also find a statistically significant increase in the incidence of having at least four visits and meeting the WHO standard. ${ }^{16}$ The density, quality and variety of health care providers is greatest on these islands, and this may have been important for facilitating the effects of health insurance. ${ }^{17}$ In contrast, access to antenatal care is less accessible and a more prominent policy concern for the other islands in the archipelago, but it is for these islands that we find no evidence of any effects. This is an important shortcoming of the Jamkesda schemes. For the other outcome variables we observe no region-specific differences.

Given that many Jamkesda schemes were motivated partly by the coverage gaps in the national insurance schemes, we also assess effect heterogeneity by wealth status. The last four columns of Table 6 shows regression results per wealth quartile. The increase in number of antenatal care visits is pronounced among the third quartile of the wealth distribution, and remains statistically significant when we apply the Romano-Wolf correction. This result coincides with the target population of most Jamkesda schemes, as this group is not expected to be eligible for subsidized social health insurance programs, while at the same time likely to be active in the informal sector and lacking access to formal sector health insurance. The estimated effect for the third quartile is sizable and accounts for the total increase in antenatal care observed for this group between 2004 and 2010. ${ }^{18}$ We observe a similar effect for births at home. While we do not find a statistically significant effect for the full population, we do see a strong negative effect for the third quartile. The size of this effect is also still considerable, with the decrease in home births accounting for about

\footnotetext{
standard errors are reported together with the Romano-Wolf p-values.

${ }^{16}$ The estimated effect on the number of antenatal care visits for Java and Bali is statistically different from the effect for the other islands (p-value 0.087).

${ }^{17}$ Including the supply of health care providers in the regression does not return meaningful results. The distribution of health care providers does not tend to vary much over time and any explanatory variation is likely absorbed by the district fixed effects. However, we cannot exclude that the results obtained are driven by the institutional quality of the health care system in Java/Bali, which is something we don't observe.

${ }^{18}$ The estimated effect for quartile 3 is statistically different from the effect for quartile 2 and 4 (p-values 0.09 and 0.03 , respectively) but not different from quartile 1 .
} 
one third of the decrease observed for this quartile over time or about 16 percent of the 2004 average (see Table A1 in the supplemental appendix). ${ }^{19}$

Turning to the type of services provided during antenatal care visits we see that the Jamkesda schemes are associated with a 4 percentage point increase (roughly 16 to 23 percent of average annual service provision) in the provision of basic recommended antenatal services (Table 7). This would represent a substantial increase over time, since during the period from 2004 to 2010 basic recommended services increased by 8 percentage points (see Table 4). However, while the clustered standard errors suggest that this effect is statistically significant, it does not pass the scrutiny of the Romano-Wolf p-values. But if we look beyond the national average, we do find results for sub-populations that stand up to multiple hypothesis testing. Consistent with the increase in the number of antenatal visits, the effect on the provision of basic recommended antenatal services is observed mainly for the third quartile and rural areas. For the other islands the impact estimate is also statistically significant, but slightly smaller. We find no evidence that the Jamkesda are associated with an increase in the share of pregnant women that receive a complete set of recommended services. In addition, for none of the individual type of services do we find Romano-Wolf p-values below 0.1 . We therefore omit these from Table $7 .^{20}$

To conclude, the effects of the Jamkesda schemes seem predominantly easily obtained gains, observed for services where barriers to (additional) utilization are already relatively low: with antenatal care, the depth of services provided during antenatal care visits, and women that would have opted for birth assistance from trained professionals now choosing to give birth at a facility rather than at home. In contrast, the results also seem to correspond with the prevailing perception in Indonesia that the incidence of births at home without professional assistance (i.e. predominantly births attended by traditional mid-

\footnotetext{
${ }^{19}$ The estimated effect for quartile 3 is statistically different from the effect for quartile 1 and 4 (p-values 0.001 and 0.006 , respectively) but not different from quartile 2 .

${ }^{20}$ The complete set of results are provided in the supplemental appendix (see Tables A7-A9).
} 
wives) is persistent and not particularly sensitive to policy interventions. Even with the expansion of births at health facilities, home births attended by traditional birth attendants, who have helped deliver previous generations within the family, are still preferred particularly in rural areas. According to qualitative evidence from our own fieldwork and also anecdotal evidence from other studies of maternal health in Indonesia, there is still a lack of trust in the professional village midwives (World Bank 2013). People have, for example, reported that they prefer to call the traditional birth attendant who is an integral part of the village rather than disturbing the village midwife. Also, often the use of the village midwife is associated with higher costs as compared to the traditional birth attendant, who is usually not formally reimbursed or reimbursed in kind (World Bank 2013).

The influence of the Jamkesda schemes' design characteristics on maternal care outcomes are presented in Table 8 . The benefits packages seem to affect the utilization of maternal care. Including prenatal and maternity care in the benefit package has a positive and statistically significant effect on the number of antenatal care visits but not on having at least four visits. ${ }^{21}$ Schemes that cover costs of delivery assistance are associated with a reduction in births at home and an increasing likelihood of births being attended by a skilled professional and birth by caesarean section, but these estimates are not precise. Including the benefits packages in the specification renders the Jamkesda coefficient statistically insignificant. This implies that the Jamkesda effect emanates entirely from the district schemes that have given greater priority to antenatal and delivery services. While perhaps an obvious point, it also suggests that such services need to be included in benefit packages if such schemes purport to influence maternal health outcomes. ${ }^{22}$

\footnotetext{
${ }^{21}$ It also has a positive effect on the probability of receiving the basic recommended antenatal care services.

${ }^{22}$ Including the benefits packages in the specification on the specific antenatal care services, i.e. weight and height measurement, blood pressure measurement, blood and urine samples, iron tablets, tetanus toxoid immunization and information on pregnancy complications also renders the Jamkesda coefficient insignificant and shows that the effects are entirely driven
} 
Variation in health care provider contracting shows mixed results. Including coverage at village health centres is associated with more antenatal care, which is a service that is typically offered in these centres or offered by providers that are directly related to the community centres, such as village midwives. However, while the coefficient is large, so are the standard errors, and the estimates are statistically insignificant. Village health centres are less inclined to deliver by caesarean section, for which we see a statistically significant decrease. Contracting district hospitals also seems to favour antenatal care, as well as reducing births at home. However, once again the effect on antenatal care is not precise. For contracts with provincial and national hospital we see a different result, as this reduces the Jamkesda impacts on both antenatal care visits and professional assistance at birth. Referrals to higher level hospitals are not (or rarely) expected to involve antenatal care or deliveries. In addition, maternal care providers such as village midwives or maternity centres are part of local health systems and networks in which village health centres and district hospitals have a key coordinating role. Contracting higher level providers such as province and national hospitals is likely to shift resources away from these networks and weaken the link of Jamkesda schemes with maternal care providers, and perhaps reduces it's impact on maternal care. Finally, we see no effect of contracting private providers.

Perhaps counter-intuitively, schemes that aim to completely fill the coverage gap are less effective in increasing antenatal care, suggesting that the ambition of universal coverage is often beyond the means of district budgets and spreads resources too thinly, which may outweigh the effect of expanding insurance coverage.

by schemes which cover maternal care services. The results are not shown but available from the authors upon request. 


\section{Conclusion}

We investigated the effect of local, district level health care financing schemes - collectively known as Jamkesda - on access and utilization of maternal care in Indonesia. The district pseudo-panel and district fixed effects identification strategy used in this paper yields causal evidence and contributes to the thus far mainly cross-section based empirical literature which has investigated the

effect of health care financing policies on maternal health care. Furthermore, decentralized public health policy in Indonesia, and the subsequent variation in health financing across districts, allowed us to investigate differences in the design of these different schemes within a single country context.

Overall, we found limited effects of the Jamkesda on maternal care, in the sense that these schemes only affect antenatal care services but not in-facility births or assisted births. Despite the already high level of antenatal care visits, the local health care financing schemes contributed to an increase in antenatal care utilization by 0.26 visits, which is four percent of average utilization but about half of the total increase observed between 2004 and 2010. Furthermore, we also found evidence that the Jamkesda contributed to improvements in the depth of antenatal care. The Jamkesda led to a four percentage point increase in the use of basic recommended antenatal care services. This effect is sizeable because quality of antenatal care services is still low and in 2010 only 27 percent of the women reported that they had received the full minimum service package comprising of measurement of weight, height, blood pressure and the testing of urine and blood samples. Thus, the findings suggest that local health care financing schemes indeed reduce financial barriers to access antenatal care services. However, they also suggest that for deliveries, considerations other than financial, play an important role, with customs and trust being important aspects that need to be overcome in order to increase the number of birth assisted by a trained professional. With the increase in the use of basic rec- 
ommended services the local schemes also seem to contribute to improving the depth of ante natal services provided, potentially due to the secured payment and reimbursement which the schemes provide.

The Jamkesda schemes have to some extent been able to address the "missing middle" coverage gaps in the national social insurance schemes. Disaggregating the results by wealth shows that the positive effects on antenatal care utilization emanate from households in the third quartile of the wealth distribution. For this group we also saw a decline in home births due to the Jamkesda. These effects for households in the third quartile suggests that the local health care financing schemes helped close the coverage gap as this group was unlikely to be covered by the subsidized social health insurance for the poor, while at the same time also unlikely to benefit from formal sector health insurance. Looking into the different features of the district schemes, we saw that the overall effect of the Jamkesda was mainly driven by schemes that explicitly cover antenatal care. This suggests that health insurance schemes might not have an effect on maternal care unless such services are covered in the benefit package.

The heterogeneity in both scheme design and estimation results provide some insight on the limitations of local schemes. The overall effect of increased access to antenatal care is mainly driven by increased access on Java and Bali, where the density and variety of health care providers and arguably also the institutional quality and capacity of the health care system is higher. However, we found no effects for the other islands, where access to antenatal care is a more pressing concern. Schemes that aimed for full population coverage or that contracted national and provincial providers of more advanced medical care, were less effective in improving maternal care. These results suggest that districts are limited in local resources and risk pools to offer the full breadth of services to a larger target population. The effectiveness of Jamkesda can be further constrained by limited human resources and administrative capacity at the district level, and in the supply and quality of local health care. 
Our findings highlight potential risks for the JKN - the new national health insurance scheme in Indonesia. First, previous studies on the Jampersal have stressed that beneficiaries need to be aware of the services on offer and their entitlements (see e.g. Achadi et al. 2014). Local governments in this context might be able to play a role in increasing local awareness. Likewise, the local health care financing schemes could be used to motivate particularly those engaged in the informal sector to voluntarily enrol in the national scheme. This is of primary importance given that voluntary enrolment in the JKN is still low (see Sato and Damayanti 2015) and the government is still pursuing the goal of reaching universal health insurance coverage by 2019. The local schemes could play an important role towards reaching this objective. However, within the current context, it still remains to be seen how these schemes will be used and integrated by 2019 . 


\section{References}

Achadi, Endang L., Anhari Achadi, Eko Pambudi and Puti Marzoeki. 2014. "A study on the implementation of Jampersal Policy in Indonesia." Health, Nutrition, and Population Discussion Paper 91325. World Bank, Washington DC.

Ahmed, Shakil, and M. Mahmud Khan. 2011. "A maternal health voucher scheme: what have we learned from the demand-side financing scheme in Bangladesh?" Health Policy $\&$ Planning 26: 25-32.

Akin, John, Paul Hutchinson and Koleman Strumpf. 2007. "Decentralisation and government provision of public goods: The public health sector in Uganda." Journal of Development Studies 41(8): 1417-1443.

Aspinall, Edward. 2014. "Health Care and democratisation in Indonesia." Democratization 21(5): 803-823.

Bellows, Nicole M., Ben W. Bellows and Charlotte Warren. 2011. "Systematic review: the use of vouchers for reproductive health services in developing countries: systematic review." Tropical Medicine 83 International Health 16: 84-96.

Borghi, Jo, Tim Ensor, Aparnaa Somanathan, Craig Lissner and Anne Mills. 2006. "Mobilising financial resources for maternal health." Lancet 368(9545): $1457-1465$.

Comfort, Alison B., Lauren A. Peterson and Laurel E. Hatt. 2013. "Effect of Health Insurance on the Use and Provision of Maternal Health Services and Maternal and Neonatal Health Outcomes." Journal of Health, Population and Nutrition 31(4) Suppl2: S81-S105.

De Allegri, Manuela, Valéry Ridde, Valérie R. Louis, Malabika Sarker, Justin Tiendrebéogo, Maurice Yé, Olaf Müller and Albrecht Jahn. 2012. "The 
impact of targeted subsidies for facility-based delivery on access to care and equity - Evidence from a population-based study in rural Burkina Faso." Journal of Public Health Policy 33: 439-453.

Dzakpasu, Susie, Timothy Powell-Jackson and Oona M. R. Campbell. 2014. "Impact of user fees on maternal health service utilization and related health outcomes: a systematic review." Health Policy $\mathcal{E}$ Planning 29(2): $137-150$.

Ekman, Björn, Indra Pathmanathan and Jerker Liljestrand. 2008. "Integrating health interventions for women, newborn babies, and children: a framework for action." Lancet 372(9642): 990-1000.

Faguet, Jean-Paul. 2004. "Does decentralisation increase government responsiveness to local needs?: Evidence from Bolivia." Journal of Public Economics 88(3-4): 867-893.

Galiani, Sebastian, Paul Gertler and Ernesto Schargrodsky. 2008. "School decentralization: Helping the good get better, but leaving the poor behind." Journal of Public Economics 92(10-11): 2106-2120.

Gani, Ascobat, Hasbullah Thabrany, Pujianto, Ferry Yanuar, Tata Tachman, Adiatma Siregar, Hudi K. Wahyu, Susilo Soerachmad, Widyastuti, Yulherina, Nurbaiti and David Dunlop. 2008. Report on assessment of health financing systems in selected districts and municipalities. Jakarta/Depok: University of Indonesia.

Gani, Ascobat, Pujianto, Ferry Yanuar, Thomas Wiechers and David Dunlop. 2009. Good practices of local health financing schemes in Indonesia: Its contribution toward universal coverage of health insurance. Jakarta/Depok: University of Indonesia.

Glassman, Amanda, Denizhan Duran and Marge Koblinsky. 2013. "Impact 
of Conditional Cash Transfers on Maternal and Newborn Health." CGD Policy Paper 019. Center for Global Development, Washington DC.

Horrace, William C. and Ronald L. Oaxaca. 2006. "Results on the bias and inconsistency of ordinary least squares for the linear probability model." Economics Letters 90(3): 321-327.

Hunter, Benjamin M., Ramila Bisht, Indira Chakravarthi and Susan F. Murray. 2014. "Demand-side Financing and Promotion of Maternal Health. What has India Learnt?" Economic $\&$ Political Weekly 49(2): 66-73.

Kruk, Margaret E., Sandro Galea, Marta Prescott and Lynn P. Freedman. 2013. "Health care financing and utilization of maternal health services in developing countries." Health Policy E Planning 22: 303-310.

Lagomarsino, Gina, Alice Garabrant, Atikah Dayas, Richard Muga and Nathaniel Otoo. 2012. "Moving towards universal health coverage: health insurance reforms in nine developing countries in Africa and Asia." Lancet 380: 933-943.

Lim, Stephen S., Lalit Dandona, Joseph A. Hoisington, Spencer L. James, Margaret C. Hogan and Emmanuela Gakidou. 2010. "India's Janani Suraksha Yojana, a conditional cash transfer programme to increase births in health facilities: an impact evaluation." Lancet 375(9730): 2009-2023.

Lin, Ann and Ahmad Shah Salehi. 2013. "Stimulating demand: effects of a conditional cash transfer programme on increasing maternal and child health-service utilisation in Afghanistan, a quasi-experimental study." Lancet 381(S2): S84.

Long, Qian, Tuohong Zhang, Ling Xu, Shenglan Tang and Elina Hemmink. 2010. "Utilisation of maternal health care in western rural China under a new rural health insurance system (New Co-operative Medical System)." Tropical Medicine 83 International Health 15(10): 1210-1217. 
Long, Qian, Reija Klemettic, Yang Wang, Fangbiao Tao, and Elina Hemminkic. 2012. "High caesarean section rate in rural China: Is it related to health insurance (New Co-operative Medical Scheme)?" Social Science $\mathcal{F}^{3}$ Medicine 75(4): 733-737.

Mensah, Joseph, Joseph R. Oppong and C Christoph M. Schmidt. 2010. "Ghana's national health insurance scheme in the context of the health MDGs: an empirical evaluation using propensity score matching." Health Economics 19(S1): 95-106.

Mohanan, Manoj, Grant Miller, Gevard La Forgia, Swapnil Shekhar and Kultar Singh. 2016. "Improving maternal and child health in India: evaluating demand and supply strategies, 3ie Impact Evaluation Report 30." New Delhi: International Initiative for Impact Evaluation (3ie).

Murray, Susan F., Benjamin M. Hunter, Ramila Bisht, Tim Ensor and Debra Bick. 2014. "Effects of demand-side financing on utilisation, experiences and outcomes of maternity care in low- and middle-income countries: a systematic review." BMC Pregnancy and Childbirth 14(30): 1-15.

Obare, Francis, Charlotte Warren, Rebecca Njuki, Timothy Abuya, Joseph Sunnday, Ian Askew and Ben Bellows. 2013. "Community-level impact of the reproductive health vouchers programme on service utilization in Kenya." Health Policy $\&$ Planning 28(2): 165-175.

Powell-Jackson, Timothy, and Kara Hanson. 2012. "Financial incentives for maternal health: Impact of a national programme in Nepal." Journal of Health Economics 31(1): 271-284.

Romano, Joseph P., and Michael Wolf. 2016. "Efficient computation of adjusted p-values for resampling-based stepdown multiple testing." Statistics $\&$ Probability Letters 113: 38-40. 
Sato, Yuri, and Arie Damayanti. 2015. "Survey of recent developments." Bulletin of Indonesian Economic Studies 51(2): 165-188.

Sparrow, Robert, Sri Budiyati, Athia Yumna, Nila Warda, Asep Suryahadi and Arjun Bedi. 2017. "Sub-national health care financing reforms in Indonesia." Health Policy and Planning 32: 91-101.

Sparrow, Robert, Asep Suryahadi and Wenefrida Widyanti. 2013. "Social health insurance for the poor: Targeting and impact of Indonesias Askeskin programme." Social Science $\&$ Medicine 96: 264-271.

United Nations Children Fund (UNICEF). 2012. Issue Briefs: Maternal and Child Health. Jakarta: UNICEF Indonesia.

Van de Poel, Ellen, Gabriela Flores, Por Ir, Owen O'Donnel and Eddy Van Doorslaer. 2014. "Can vouchers deliver? An evaluation of subsidies for maternal health care in Cambodia." Bulletin of the World Health Organisation 92: 331-339.

World Bank. 2013. A Study on the Implementation of Jampersal Policy in Indonesia. Jakarta: World Bank.

World Health Organization. 2010. The World Health Report - Health systems financing: the path to universal coverage. Geneva: World Health Organization. 


\section{Figures}

Figure 1: Coverage of the district survey

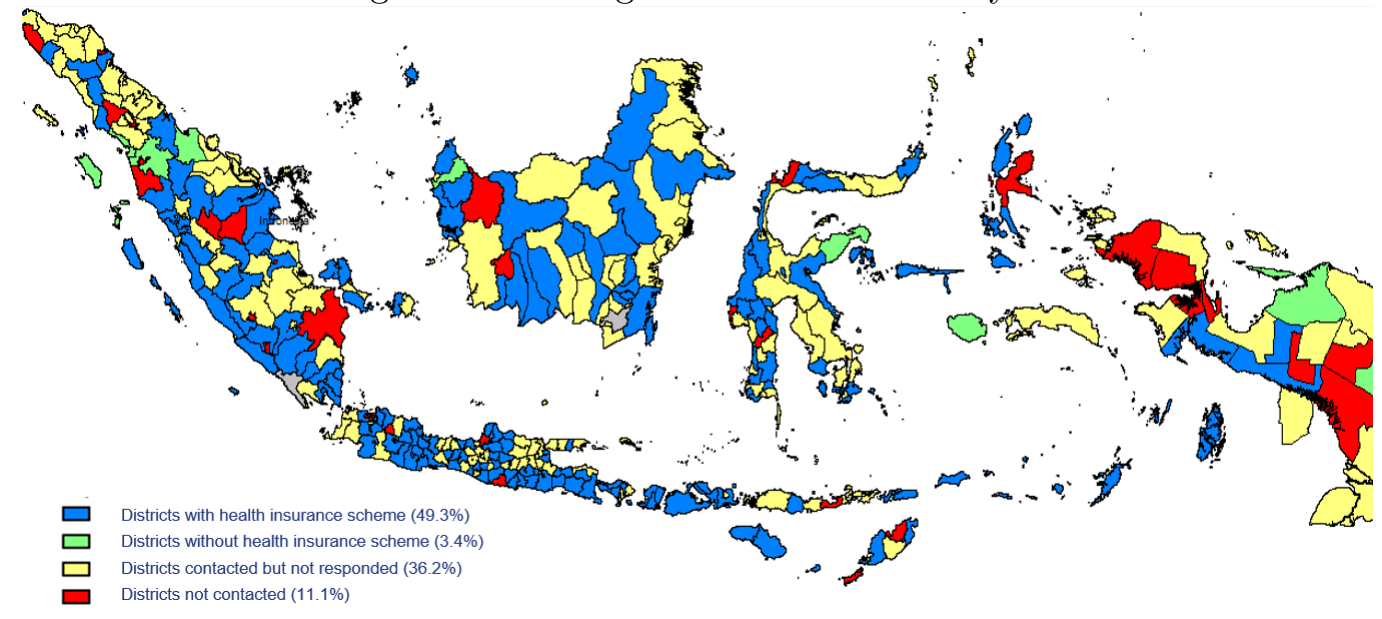


Figure 2: Expansion of Jamkesda schemes over time

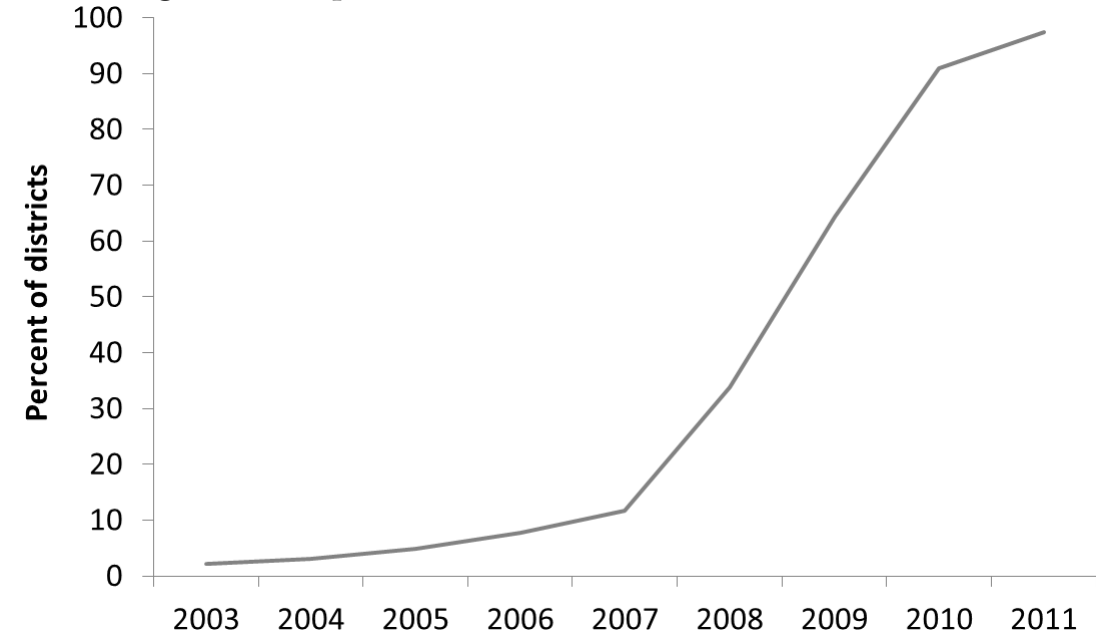




\section{Tables}

Table 1: Descriptive statistics of individual data and district characteristics

\begin{tabular}{lcc} 
& Mean & SD \\
\hline Panel A: Individual level data (IDHS; N=10,856) & & \\
Child male (=1) & 0.51 & \\
Birth order & 2.36 & 1.58 \\
Recall period of birth (months) & 29.48 & 15.24 \\
Mother age at birth (years) & 27.93 & 6.24 \\
Mother years of education & 8.89 & 4 \\
Married (=1) & 0.97 & 0.18 \\
Number of children born & 2.5 & \\
Rural (=1) & 0.58 & 0.49 \\
Head male (=1) & 0.93 & \\
Number of HH members & 5.46 & 2.2 \\
Quartile 1, poorest (=1) & 0.21 & \\
Quartile 2 & 0.25 & \\
Quartile 3 & 0.26 & \\
Quartile 4, wealthiest (=1) & 0.28 & \\
Panel B: District information (PODES, SUSENAS; N=2000) & & \\
\% subsidized SHI & 0.14 & 0.16 \\
\% formal sector SHI & 0.1 & 0.07 \\
\% private HI & 0.05 & 0.09 \\
\% other HI & 0.01 & 0.02 \\
\% of electrified HH in district & 0.62 & 0.27 \\
\% of villages with water from pump & 0.24 & 0.26 \\
\% of villages with water from well & 0.47 & 0.28 \\
\% of villages with asphalt road & 0.64 & 0.27 \\
\% of villages with doctor & 0.96 & 0.05 \\
\% of villages with midwife & 0.43 & 0.34 \\
\% of villages with traditional birth assistant & 0.82 & 0.17 \\
\hline Notes Stag head & 0.86 & 0.2 \\
\hline
\end{tabular}

Notes: Standard deviations are not reported for binary variables.

Source: IDHS (2007, 2012), SUSENAS (2003-2009), PODES (2003, 2006, 2008). 
Table 2: Design characteristics of Jamkesda schemes

\begin{tabular}{lr}
\hline & Percent of districts \\
\hline Service coverage & \\
Antenatal care & 34.6 \\
Delivery assistance & 23.9 \\
Provider characteristics & \\
Village health centre & 91.9 \\
District public hospital & 88.0 \\
Province or national public hospital & 81.6 \\
Hospital in other district or province & 40.6 \\
Private hospital & 25.2 \\
Population coverage & 32.9 \\
Universal coverage as objective & \\
\hline Source: DHO survey 2011/2012. The table shows characteristics for \\
the DHO survey subsample of 234 districts that also appear in the \\
IDHS 2007 and 2012 surveys.
\end{tabular}


Table 3: Evolution of outcome measures over time

\begin{tabular}{lccccccc}
\hline & 2004 & 2005 & 2006 & 2007 & 2008 & 2009 & 2010 \\
\hline Number of antenatal care visits & 6.8 & 6.68 & 6.7 & 6.83 & 7.45 & 7.38 & 7.3 \\
4+ antenatal care visits $(=1)$ & 0.81 & 0.82 & 0.81 & 0.82 & 0.89 & 0.88 & 0.87 \\
Delivery at home (=1) & 0.58 & 0.55 & 0.51 & 0.47 & 0.45 & 0.4 & 0.39 \\
Birth assisted by trained professional $(=1)$ & 0.29 & 0.3 & 0.32 & 0.59 & 0.41 & 0.43 & 0.46 \\
Caesarean (=1) & 0.06 & 0.06 & 0.08 & 0.09 & 0.11 & 0.12 & 0.14 \\
\hline
\end{tabular}

Source: IDHS (2007, 2012). 
Table 4: Antenatal services received and evolution over time

\begin{tabular}{lccccccc}
\multicolumn{7}{c}{ Table 4: Antenatal services received and evolution over time } \\
\hline & 2004 & 2005 & 2006 & 2007 & 2008 & 2009 & 2010 \\
\hline Weight measurement $(=1)$ & 0.69 & 0.81 & 0.86 & 0.75 & 0.71 & 0.79 & 0.85 \\
Height measurement $(=1)$ & 0.35 & 0.33 & 0.36 & 0.36 & 0.48 & 0.5 & 0.47 \\
Blood pressure measurement $(=1)$ & 0.91 & 0.91 & 0.92 & 0.92 & 0.95 & 0.95 & 0.95 \\
Testing of blood and urine samples $(=1)$ & 0.4 & 0.38 & 0.39 & 0.4 & 0.47 & 0.47 & 0.44 \\
Iron tablets (=1) & 0.8 & 0.78 & 0.8 & 0.79 & 0.76 & 0.75 & 0.74 \\
Tetanus toxoid immunization (=1) & 0.79 & 0.76 & 0.78 & 0.75 & 0.78 & 0.76 & 0.76 \\
Information of signs of pregnancy complications $(=1)$ & 0.41 & 0.39 & 0.4 & 0.44 & 0.55 & 0.54 & 0.53 \\
& & & & & & & \\
Basic recommended services a) (=1) & 0.19 & 0.18 & 0.21 & 0.21 & 0.27 & 0.28 & 0.27 \\
Complete set of recommended services received $(=1)$ & 0.1 & 0.08 & 0.09 & 0.1 & 0.13 & 0.15 & 0.14 \\
\hline
\end{tabular}

Notes: Data on abdominal examinations is not consistently available in the DHS survey rounds. a) Basic recommended services include measurement of weight, height and blood pressure, and testing of blood and urine samples.

Source: IDHS (2007, 2012). 
Table 5: Effect of the Jamkesda schemes ( $\mathrm{N}=10,856$ across 234 districts)

\begin{tabular}{lccccccc}
\hline & $(1)$ & $(2)$ & $(3)$ & $(4)$ & $(5)$ & $(6)$ & Mean \\
\hline Number of antenatal care visits & $0.679^{* *}$ & 0.210 & $0.260^{*}$ & $0.255+$ & $0.251+$ & -0.030 & 7.02 \\
& $(0.114)$ & $(0.140)$ & $(0.132)$ & $(0.133)$ & $(0.132)$ & $(0.124)$ & \\
4+ antenatal care visits $(=1)$ & $0.070^{* *}$ & 0.023 & 0.027 & 0.028 & 0.026 & 0.023 & 0.84 \\
& $(0.014)$ & $(0.017)$ & $(0.017)$ & $(0.017)$ & $(0.017)$ & $(0.015)$ & \\
Delivery at home (=1) & $-0.119^{* *}$ & -0.028 & -0.019 & -0.017 & -0.018 & -0.002 & 0.47 \\
& $(0.016)$ & $(0.019)$ & $(0.019)$ & $(0.019)$ & $(0.019)$ & $(0.014)$ & \\
Birth assisted by trained professional $(=1)$ & $0.038+$ & -0.001 & -0.005 & -0.007 & -0.006 & -0.004 & 0.42 \\
& $(0.020)$ & $(0.024)$ & $(0.025)$ & $(0.025)$ & $(0.024)$ & $(0.020)$ & \\
Caesarean $(=1)$ & $0.065^{* *}$ & 0.020 & 0.019 & 0.020 & 0.020 & -0.011 & 0.10 \\
& $(0.011)$ & $(0.013)$ & $(0.013)$ & $(0.013)$ & $(0.013)$ & $(0.011)$ & \\
\hline
\end{tabular}

Controls

District fixed effect

Year dummies, household characteristics

District characteristics

Direct elections district regent/mayor

Sample selection term

$\begin{array}{llllll}\text { Yes } & \text { Yes } & \text { Yes } & \text { Yes } & \text { Yes } & \text { Yes } \\ \text { No } & \text { Yes } & \text { Yes } & \text { Yes } & \text { Yes } & \text { Yes } \\ \text { No } & \text { No } & \text { Yes } & \text { Yes } & \text { Yes } & \text { Yes } \\ \text { No } & \text { No } & \text { No } & \text { Yes } & \text { No } & \text { No } \\ \text { No } & \text { No } & \text { No } & \text { No } & \text { Yes } & \text { No }\end{array}$

Notes: Control variables omitted for convenience. Column (6) reports placebo regression results. Standard errors clustered at district level in parenthesis.

Statistical significance: ${ }^{* *} p<0.01, * p<0.05,+p<0.10$.

Source: IDHS (2007, 2012), SUSENAS (2003-2009), PODES (2003, 2006, 2008), DHO survey 2011/2012. 
Table 6: Effect of the Jamkesda schemes by rural/urban locations, region and wealth quartile

\begin{tabular}{|c|c|c|c|c|c|c|c|c|}
\hline & Rural & Urban & $\begin{array}{c}\text { Java \& } \\
\text { Bali }\end{array}$ & $\begin{array}{l}\text { Other } \\
\text { islands }\end{array}$ & $\begin{array}{c}\text { Quartile } 1 \\
\text { (poorest) }\end{array}$ & Quartile 2 & Quartile 3 & $\begin{array}{c}\text { Quartile } 4 \\
\text { (wealthiest) }\end{array}$ \\
\hline \multirow[t]{3}{*}{ Number of antenatal care visits } & 0.168 & 0.229 & $0.657^{*}$ & 0.089 & 0.413 & 0.023 & $0.590^{*}$ & -0.046 \\
\hline & $(0.180)$ & $(0.208)$ & $(0.300)$ & $(0.150)$ & $(0.350)$ & $(0.245)$ & $(0.244)$ & $(0.205)$ \\
\hline & {$[0.579]$} & {$[0.465]$} & {$[0.058]$} & {$[0.705]$} & {$[0.465]$} & {$[0.914]$} & {$[0.094]$} & {$[0.903]$} \\
\hline \multirow{3}{*}{$4+$ antenatal care visits $(=1)$} & 0.030 & 0.015 & $0.058+$ & 0.011 & 0.057 & 0.015 & $0.059^{*}$ & -0.016 \\
\hline & $(0.025)$ & $(0.021)$ & $(0.030)$ & $(0.020)$ & $(0.051)$ & $(0.030)$ & $(0.029)$ & $(0.019)$ \\
\hline & {$[0.503]$} & {$[0.698]$} & {$[0.061]$} & {$[0.698]$} & {$[0.503]$} & {$[0.698]$} & {$[0.142]$} & {$[0.698]$} \\
\hline \multirow[t]{3}{*}{ Delivery at home $(=1)$} & -0.024 & 0.017 & 0.003 & -0.020 & 0.043 & -0.034 & $-0.084^{* *}$ & 0.022 \\
\hline & $(0.027)$ & $(0.025)$ & $(0.036)$ & $(0.023)$ & $(0.030)$ & $(0.036)$ & $(0.032)$ & $(0.027)$ \\
\hline & {$[0.671]$} & {$[0.676]$} & {$[0.923]$} & {$[0.656]$} & {$[0.613]$} & {$[0.676]$} & {$[0.046]$} & {$[0.676]$} \\
\hline \multirow[t]{3}{*}{ Birth assisted by trained professional $(=1)$} & -0.026 & -0.007 & 0.029 & -0.026 & -0.038 & 0.004 & 0.022 & 0.019 \\
\hline & $(0.032)$ & $(0.031)$ & $(0.038)$ & $(0.029)$ & $(0.042)$ & $(0.045)$ & $(0.046)$ & $(0.039)$ \\
\hline & {$[0.780]$} & {$[0.918]$} & {$[0.820]$} & {$[0.773]$} & {$[0.780]$} & {$[0.919]$} & {$[0.875]$} & {$[0.875]$} \\
\hline \multirow[t]{3}{*}{ Caesarean $(=1)$} & 0.009 & 0.029 & 0.041 & 0.008 & 0.008 & -0.025 & 0.042 & $0.052+$ \\
\hline & $(0.017)$ & $(0.021)$ & $(0.032)$ & $(0.014)$ & $(0.016)$ & $(0.026)$ & $(0.028)$ & $(0.030)$ \\
\hline & {$[0.740]$} & {$[0.413]$} & {$[0.402]$} & {$[0.740]$} & {$[0.740]$} & {$[0.582]$} & {$[0.384]$} & {$[0.374]$} \\
\hline Number of observations & 6,318 & 4,538 & 3,369 & 7,487 & 2,324 & 2,671 & 2,847 & 3,014 \\
\hline
\end{tabular}

Notes: Specification similar to column (3) of Table 5. Control variables include demographic and household characteristics, district characteristics, and district fixed effects. Control variables omitted for convenience. Standard errors clustered at district level in parenthesis. Romano-Wolf (2016) multiple hypothesis test p-values, based on regression results in each row, in square brackets (1,000 replications).

Statistical significance: ${ }^{* *} p<0.01,{ }^{*} p<0.05,+p<0.10$.

Source: IDHS (2007, 2012), SUSENAS (2003-2009), PODES (2003, 2006, 2008), DHO survey 2011/2012. 
Table 7: Effect of the Jamkesda schemes on quality of antenatal care by rural/urban locations, region and wealth quartile

\begin{tabular}{|c|c|c|c|c|c|c|c|c|c|}
\hline & All & Rural & Urban & $\begin{array}{c}\text { Java \& } \\
\text { Bali }\end{array}$ & $\begin{array}{l}\text { Other } \\
\text { islands }\end{array}$ & $\begin{array}{c}\text { Quartile } 1 \\
\text { (poorest) }\end{array}$ & Quartile 2 & Quartile 3 & $\begin{array}{c}\text { Quartile } 4 \\
\text { (wealthiest) }\end{array}$ \\
\hline \multirow{3}{*}{ Basic recommended services $(=1)$} & $0.043+$ & $0.073^{*}$ & 0.016 & $0.082+$ & 0.020 & -0.012 & -0.023 & $0.112^{*}$ & 0.041 \\
\hline & $(0.024)$ & $(0.034)$ & $(0.038)$ & $(0.048)$ & $(0.028)$ & $(0.050)$ & $(0.052)$ & $(0.045)$ & $(0.050)$ \\
\hline & {$[0.258]$} & {$[0.077]$} & {$[0.813]$} & {$[0.235]$} & {$[0.753]$} & {$[0.813]$} & {$[0.813]$} & {$[0.077]$} & {$[0.749]$} \\
\hline \multirow[t]{3}{*}{ Complete set of rec. services $(=1)$} & -0.007 & 0.014 & -0.016 & 0.002 & -0.011 & -0.031 & -0.026 & 0.013 & 0.004 \\
\hline & $(0.020)$ & $(0.025)$ & $(0.033)$ & $(0.038)$ & $(0.022)$ & $(0.039)$ & $(0.034)$ & $(0.035)$ & $(0.042)$ \\
\hline & {$[0.786]$} & {$[0.900]$} & {$[0.906]$} & {$[0.955]$} & {$[0.906]$} & {$[0.872]$} & {$[0.900]$} & {$[0.906]$} & {$[0.952]$} \\
\hline Number of observations & 10,856 & 6,318 & 4,538 & 3,369 & 7,487 & 2,324 & 2,671 & 2,847 & 3,014 \\
\hline
\end{tabular}

Notes: Specification similar to column (3) of Table 5. Control variables include demographic and household characteristics, district characteris-

tics, and district fixed effects. Control variables omitted for convenience. Standard errors clustered at district level in parenthesis. Romano-Wolf (2016) multiple hypothesis test p-values, based on regression results in each row, in square brackets (1,000 replications). Basic recommended services include measurement of weight, height and blood pressure, and testing of blood and urine samples. The complete set of recommended services additionally includes providing iron tablets, tetanus toxoid immunization, and information on pregnancy complications.

Statistical significance: $* * p<0.01, * p<0.05,+p<0.10$.

Source: IDHS (2007, 2012), SUSENAS (2003-2009), PODES (2003, 2006, 2008), DHO survey 2011/2012. 
Table 8: Effect of Jamkesda design characteristics

\begin{tabular}{|c|c|c|c|c|c|}
\hline & $\begin{array}{l}\text { Number of ANC } \\
\text { visits }\end{array}$ & $\begin{array}{l}4+\underset{\mathrm{ANC}}{\mathrm{Aisits}} \\
\text { vis }\end{array}$ & $\begin{array}{l}\text { Delivery at } \\
\text { home }\end{array}$ & $\begin{array}{l}\text { Birth ass. by } \\
\text { trained prof. }\end{array}$ & Caesarean \\
\hline Jamkesda $(=1)$ & $\begin{array}{c}0.056 \\
(0.588)\end{array}$ & $\begin{array}{c}0.082 \\
(0.071)\end{array}$ & $\begin{array}{c}0.001 \\
(0.064)\end{array}$ & $\begin{array}{c}0.017 \\
(0.094)\end{array}$ & $\begin{array}{l}0.137^{*} \\
(0.063)\end{array}$ \\
\hline \multicolumn{6}{|l|}{ Service coverage } \\
\hline Antenatal care $(=1)$ & $\begin{array}{l}0.754^{*} \\
(0.294)\end{array}$ & $\begin{array}{c}0.037 \\
(0.0380\end{array}$ & $\begin{array}{c}0.048 \\
(0.040)\end{array}$ & $\begin{array}{l}-0.024 \\
(0.042)\end{array}$ & $\begin{array}{l}-0.034 \\
(0.021)\end{array}$ \\
\hline Delivery assistance $(=1)$ & $\begin{array}{l}-0.221 \\
(0.317)\end{array}$ & $\begin{array}{c}0.004 \\
(0.042)\end{array}$ & $\begin{array}{l}-0.077 \\
(0.050)\end{array}$ & $\begin{array}{c}0.059 \\
(0.056)\end{array}$ & $\begin{array}{c}0.030 \\
(0.025)\end{array}$ \\
\hline \multicolumn{6}{|l|}{ Provider characteristics } \\
\hline Village health centre $(=1)$ & $\begin{array}{c}0.370 \\
(0.437)\end{array}$ & $\begin{array}{l}-0.031 \\
(0.037)\end{array}$ & $\begin{array}{c}0.023 \\
(0.052)\end{array}$ & $\begin{array}{c}0.009 \\
(0.059)\end{array}$ & $\begin{array}{c}-0.099+ \\
(0.059)\end{array}$ \\
\hline Dist. pub. hospital $(=1)$ & $\begin{array}{c}0.458 \\
(0.343)\end{array}$ & $\begin{array}{c}0.053 \\
(0.052)\end{array}$ & $\begin{array}{c}-0.114^{*} \\
(0.048)\end{array}$ & $\begin{array}{c}0.077 \\
(0.075)\end{array}$ & $\begin{array}{c}0.027 \\
(0.035)\end{array}$ \\
\hline Prov./nat. publ. hospital (=1) & $\begin{array}{l}-0.726^{*} \\
(0.316)\end{array}$ & $\begin{array}{c}-0.0802+ \\
(0.048)\end{array}$ & $\begin{array}{c}0.060 \\
(0.045)\end{array}$ & $\begin{array}{l}-0.102^{*} \\
(0.046)\end{array}$ & $\begin{array}{l}-0.038 \\
(0.031)\end{array}$ \\
\hline Hospital in other dist./prov. $(=1)$ & $\begin{array}{c}0.112 \\
(0.198)\end{array}$ & $\begin{array}{c}0.034 \\
(0.023)\end{array}$ & $\begin{array}{c}0.019 \\
(0.031)\end{array}$ & $\begin{array}{c}0.005 \\
(0.042)\end{array}$ & $\begin{array}{l}-0.004 \\
(0.024)\end{array}$ \\
\hline Private hospital $(=1)$ & $\begin{array}{l}-0.089 \\
(0.210)\end{array}$ & $\begin{array}{l}-0.036 \\
(0.024)\end{array}$ & $\begin{array}{c}0.012 \\
(0.031)\end{array}$ & $\begin{array}{l}-0.033 \\
(0.042)\end{array}$ & $\begin{array}{l}-0.029 \\
(0.026)\end{array}$ \\
\hline \multicolumn{6}{|l|}{ Further characteristics } \\
\hline Universal coverage $(=1)$ & $\begin{array}{c}-0.614^{* *} \\
(0.235)\end{array}$ & $\begin{array}{c}-0.070^{*} \\
(0.035)\end{array}$ & $\begin{array}{l}-0.015 \\
(0.031)\end{array}$ & $\begin{array}{l}-0.018 \\
(0.044)\end{array}$ & $\begin{array}{c}0.007 \\
(0.020)\end{array}$ \\
\hline \multicolumn{6}{|l|}{ Controls } \\
\hline District fixed effects & Yes & Yes & Yes & Yes & Yes \\
\hline Year dummies, HH char. & Yes & Yes & Yes & Yes & Yes \\
\hline District characteristics & Yes & Yes & Yes & Yes & Yes \\
\hline Number of observations & 9,135 & 9,135 & 10,761 & 7,490 & 10,776 \\
\hline Adjusted R-squared & 0.144 & 0.092 & 0.162 & 0.131 & 0.054 \\
\hline
\end{tabular}

rrors clustered at district level in parenthesis.

Statistical significance: ${ }^{* *} p<0.01,{ }^{*} p<0.05,+p<0.10$.

Source: IDHS (2007, 2012), SUSENAS (2003-2009), PODES (2003, 2006, 2008), DHO survey 2011/2012. 